\title{
Case report. Een paraganglioom in de blaas
}

\author{
Iris Muller ${ }^{1}$ Bernard A. Zonnenberg ${ }^{2}$ Trudy G. N. Jonges ${ }^{3}$ Tycho M. T. W. Lock ${ }^{1,4}$
}

Published online: 27 September 2016

(c) The Author(s) 2016. This article is available at SpringerLink with Open Access.

Samenvatting Wij beschrijven een casus van een 48-jarige vrouw met een atypische blaastumor. Patiënt is bekend met familiaire paragangliomen. Een catecholamineproducerende blaastumor zou tijdens een operatie een plotselinge bloeddrukstijging kunnen veroorzaken als gevolg van een catecholaminecrisis. Uit voorzorg werden daarom, voorafgaand aan de resectie van de blaastumor, de catecholaminereceptoren (met name de alfareceptoren) geblokkeerd. Er werd een transurethrale resectie gedaan van een blaastumor met een doorsnee van $1 \mathrm{~cm}$. Pathologisch onderzoek bevestigde de diagnose; het bleek inderdaad te gaan om een paraganglioom van de blaas.

Trefwoorden paraganglioom $\cdot$ neoplasma $\cdot$ blaas $\cdot$ neuro-endocriene tumor

\section{Case report. Bladder pheochromocytoma}

Abstract We report a case of a 48 -year-old female with an atypical bladder tumor. The patient has a history of familial paraganglioma. A catecholamine releasing bladder tumor could cause an adrenal crisis with sudden hyperten-

drs. Iris Muller

mulleriris@gmail.com

1 afdeling Urologie, Universitair Medisch Centrum Utrecht, Utrecht, Nederland

2 afdeling Interne geneeskunde, Universitair Medisch Centrum Utrecht, Utrecht, Nederland

3 afdeling Pathologie, Universitair Medisch Centrum Utrecht, Utrecht, Nederland

4 afdeling Urologie, Centraal Militair Hospitaal, Utrecht, Nederland sion during surgery. Therefore, the catecholamine receptors were blocked prior to the resection of the bladder tumor. A transurethral resection of an $1 \mathrm{~cm}$ large bladder tumor was performed. Pathological examination confirmed the diagnosis; it indeed turned out to be a bladder pheochromocytoma.

Keywords paraganglioma $\cdot$ neoplasm $\cdot$ bladder . neuroendocrine tumor

\section{Casus}

Een 48-jarige vrouw meldt zich op de polikliniek Gynaecologie met klachten van een balgevoel, dat erger wordt naarmate de dag vordert. Haar voorgeschiedenis vermeldt paragangliomen (familiair) op basis van een SDHD-genmutatie. Bij lichamelijk onderzoek blijkt er sprake te zijn van een verzakking van de voorwand van de blaas. Gezien haar voorgeschiedenis wordt nadere analyse verricht door middel van een CT-scan van het abdomen. Op de CTabdomen is, dorsaal in de blaas, een laesie van $11 \mathrm{~mm}$ te zien. Op grond hiervan wordt patiënte verwezen naar de uroloog. Zij heeft geen mictieklachten en geen blaasontstekingen doorgemaakt, nooit bloed bij de urine gezien en er is geen sprake van incontinentie. Bij lichamelijk onderzoek wordt een bloeddruk van 130/81 mm $\mathrm{Hg}$ gemeten, waarbij opvalt dat zij hartkloppingen krijgt en dat haar bloeddruk stijgt op het moment dat zij aandrang krijgt. Bij cystoscopie wordt op de blaasbodem een tumor gezien van ongeveer $1 \mathrm{~cm}$ doorsnee, met uitgebreide vaattekening. De tumor is glad en lijkt niet invasief te groeien (fig. 1).

Laboratoriumonderzoek laat geen afwijkingen zien. Ook de 24-uursurine heeft normale waarden: metanefrine $0,4 \mathrm{nmol} / 24 \mathrm{u}$ (referentiewaarde $0-1,8$ ), normetanefrine 


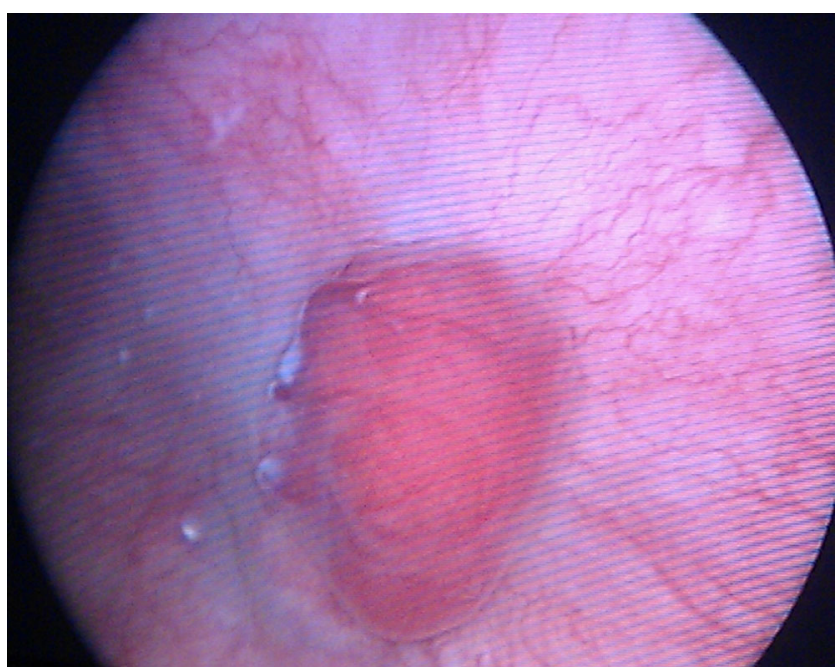

Figuur 1 Tumor met uitgebreide vaattekening.

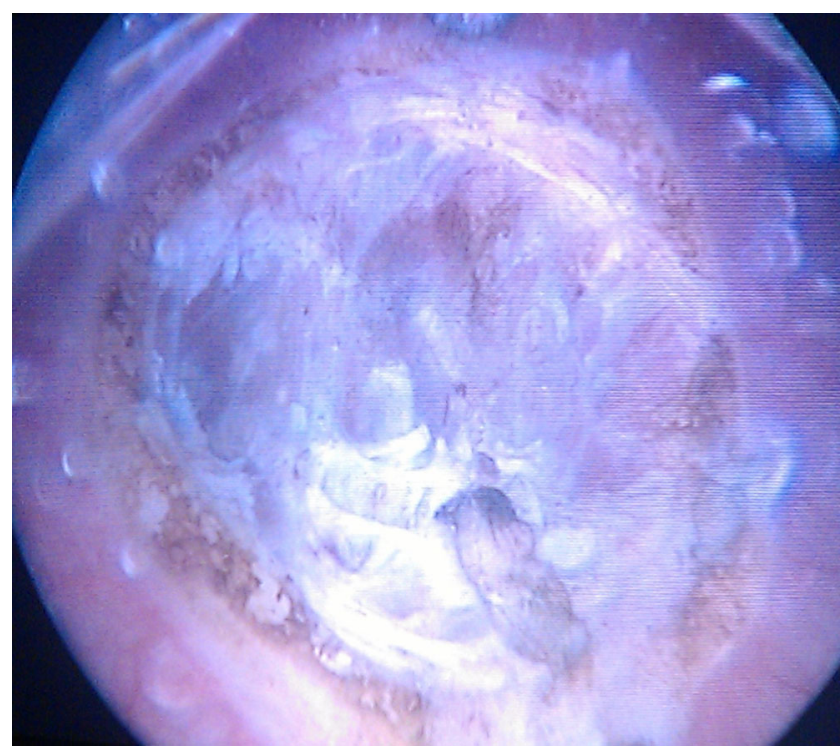

Figuur 2 Beeld na transurethrale resectie.

$1,8 \mathrm{nmol} / 24$ u (referentiewaarde $0-3,3$ ), vrij adrenaline $28 \mathrm{nmol} / 24 \mathrm{u}$ (referentiewaarde $0-100$ ), vrij noradrenaline $290 \mathrm{nmol} / 24$ u (referentiewaarde 90-470), vrij dopamine $1388 \mathrm{nmol} / 24 \mathrm{u}$ (referentiewaarde 420-2600).

Gezien de voorgeschiedenis en het atypische beeld bij de cystoscopie is er een verdenking op een catecholamineproducerende blaastumor. Dit zijn paragangliomen, die bij aanraking een forse cathecholaminerelease kunnen hebben. Voorafgaand aan de chirurgische verwijdering worden daarom de alfareceptoren geblokkeerd. Dit gebeurt preoperatief op de afdeling Interne Geneeskunde door middel van Cardura $^{\circledR}$. De bloeddruk vertoont preoperatief geen schommelingen meer.

De blaastumor wordt operatief verwijderd door middel van een transurethrale resectie (TUR) met manuele onder-

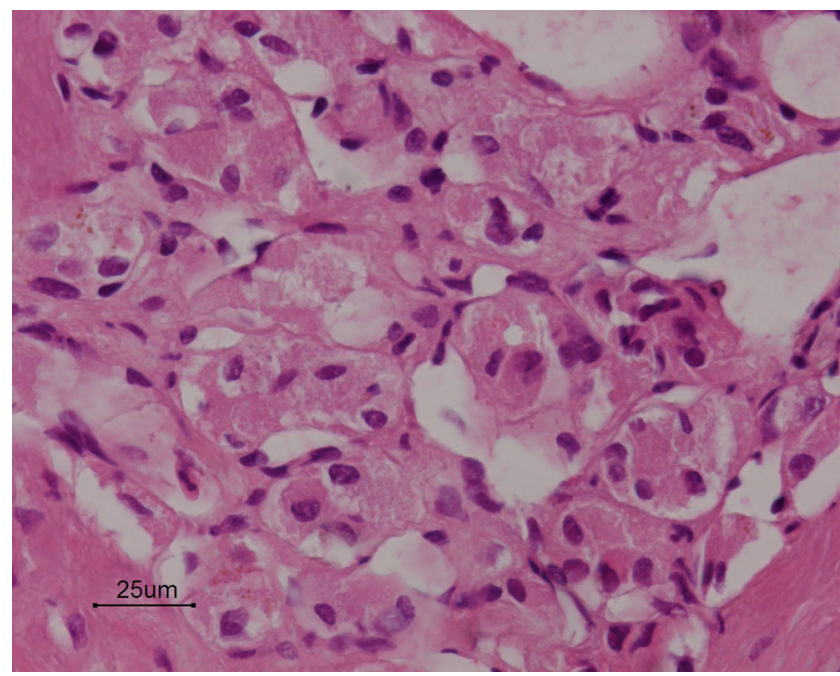

Figuur 3 Paragangliomen tonen karakteristieke geneste cellen (zellballen) met een overvloed aan cytoplasma.

steuning via de vagina. Ook peroperatief is de bloeddruk van patiënte stabiel. Er wordt een goed afgegrensde tumor van $1 \mathrm{~cm}$ doorsnee verwijderd (fig. 2). Pathologisch onderzoek wijst uit dat er inderdaad sprake was van een paraganglioom (fig. 3).

Een cystoscopie na vier maanden toonde geen recidief. De bloeddruk blijft stabiel. Verdere follow-up gebeurde middels CT en MRI (hoge sensitiviteit voor het vinden van een paraganglioom in de blaas), welke tot op heden geen recidief in de blaas lieten zien.

\section{Beschouwing}

\section{Incidentie}

Zimmerman was in 1953 de eerste die een paraganglioom in de blaas beschreef [1]. Een paraganglioom is een zeldzame aandoening waarover tot nu toe ongeveer 200 casus zijn verschenen in de literatuur [2,3]. Extra-adrenale feochromocytomen (paragangliomen) komen het meeste voor bij jongvolwassen vrouwen die bij presentatie gemiddeld 45 jaar oud zijn [4]. Paragangliomen van de blaas omvatten $0,06 \%$ van alle blaastumoren en $6 \%$ van de extraadrenale feochromocytomen [5].

\section{Pathologie}

Paragangliomen van de blaas ontstaan uit embryonale nestjes van chromaffiene cellen vanuit de sympathische plexus van de $\mathrm{m}$. detrusor. Een deel van deze cellen is hormonaal actief (catecholamineproductie). Deze activiteit kan zich uiten in hypertensie bij blaaslediging, blaasvulling, defe- 
catie of seksueel contact. Zelfs een cystoscopie kan een hypertensieve crises veroorzaken.

\section{Klinische presentatie}

Bij de klassieke presentatie van een feochromocytoom heeft de patiënt perioden met hoofdpijn, zweten, verstoorde visus en hartkloppingen. Een paraganglioom in de blaas kan daarnaast hematurie $(33 \%)$ en intermitterende hypertensie (tijdens de mictie) (50\%) veroorzaken [4]. De tumor kan zich echter ook asymptomatisch presenteren [7].

\section{Diagnostiek}

In sommige gevallen kan de diagnose worden bevestigd door een catecholaminestijging in het plasma en/of in de 24-uursurine. Deze testen leveren echter niet altijd afwijkende resultaten op [7]. Bij cystoscopie wordt meestal een submucosale of intramurale laesie gezien met intact epitheel $(71 \%)$, waarbij soms sprake is van hypervascularisatie van de mucosa. De gemiddelde doorsnee van de tumor is $2 \mathrm{~cm} \mathrm{[2,6].} \mathrm{Het} \mathrm{nemen} \mathrm{van} \mathrm{een} \mathrm{biopt} \mathrm{kan} \mathrm{leiden} \mathrm{tot} \mathrm{een}$ plotselinge bloeddrukstijging, die leidt tot een catecholaminecrisis, en wordt dus niet geadviseerd [7].

Differentiaaldiagnostisch kan gedacht worden aan urotheelcelcarcinoom, rabdomyosarcoom, hemangioom, leiomyoom, neurofibroom, granulaire celtumoren, maligne melanoom en cystitis.

\section{Behandeling}

De symptomen van de overmatige catecholamineproductie kunnen behandeld worden met een gecombineerde alfa- en bèta-adrenerge blokkade.

Verwijderen van een paraganglioom uit de blaas kan door middel van een transurethrale resectie, een partiële of een radicale cystectomie en, bij grote tumoren, met pelviene klierdissectie. De partiële cystectomie wordt het vaakst toegepast. Een transurethrale resectie is meestal niet afdoende, aangezien de laesie vanuit de musculus detrusor ontstaat [2]. Voorafgaand aan de resectie zullen de alfa- en bètareceptoren volledige geblokkeerd moeten worden om een hypertensieve crisis te voorkomen. Niet alle paragangliomen produceren echter catecholamine. Er zijn ook patiënten bij wie paragangliomen zonder blokkade zijn verwijderd, bij wie geen hemodynamische veranderingen optraden [6, 7].

\section{Conclusie}

Bij patiënten met een familiair paraganglioom moet worden gedacht aan een extra-adrenale lokalisatie van een tumor in de blaas. De diagnose wordt gesteld op grond van de combinatie: klinische presentatie, beeld bij cystoscopie en endocrinologisch onderzoek. Bij de behandeling van deze tumoren is optimale blokkade van de catecholaminereceptoren vereist, gezien het risico op een catecholaminecrisis.

Open Access. This article is distributed under the terms of the Creative Commons Attribution 4.0 International License (http:// creativecommons.org/licenses/by/4.0/), which permits unrestricted use, distribution, and reproduction in any medium, provided you give appropriate credit to the original author(s) and the source, provide a link to the Creative Commons license, and indicate if changes were made.

\section{Literatuur}

1. Zimmerman IJ, Biron RE, MacMahon HE. Pheochromocytoma of the urinary bladder. N Engl J Med. 1953;249(1):25-6.

2. Das S, Bulusu NV, Lowe P. Primary vesical pheochromocytoma. Urology. 1983;21(1):20-5.

3. Whalen RK, Althausen AF, Daniels GH. Extra-adrenal pheochromocytoma. J Urol. 1992;147(1):1-10.

4. Cheng L, Leibovich BC, Cheville JC, Ramnani DM, Sebo TJ, Neumann RM, et al. Paraganglioma of the urinary bladder: Can biologic potential be predicted? Cancer. 2000;88(4):844-52.

5. Leestma JE, Price EB Jr. Paraganglioma of the urinary bladder. Cancer. 1971;28(4):1063-73.

6. Xu DF, Chen M, Liu YS, Gao Y, Cui XG. Non-functional paraganglioma of the urinary bladder: a case report. J Med Case Rep. 2010;4:216.

7. Baima C, Casetta G, Vella R, Tizzani A. Bladder pheochromocytoma: a 3-year follow-up after transurethral resection (TURB). Urol Int. 2000;65(3):176-8.

drs. Iris Muller arts-assistent urologie

dr. Bernard A. Zonnenberg internist

dr. Trudy G.N. Jonges patholoog

drs. Tycho M.T.W. Lock uroloog FEBU 